\title{
Carbon Recycling for Renewable Materials and Energy Supply
}

Recent Trends, Long-Term Options, and Challenges for Research and Development

Originally published as:

Stefan Bringezu (2014):

Carbon Recycling for Renewable Materials and Energy Supply - Recent Trends, Long-Term Options, and Challenges for Research and Development

In: Journal of Industrial Ecology 2014, Vol. 18, Issue 3, 327-340 
Stefan Bringezu a,b

\section{Carbon Recycling for Renewable Materials and Energy Supply}

Recent Trends, Long-Term Options, and Challenges for Research and Development

\footnotetext{
a Wuppertal Institute for Climate, Environment and Energy (WI) Wuppertal, Germany

b Center for Environmental Systems Research (CESR) at the University of Kassel, Germany
}

E-mail: stefan.bringezu@wupperinst.org

Phone: +49 202-2492139

Fax: +49 202-2492138 


\section{Carbon Recycling for Renewable Materials and Energy Supply:}

2 Recent trends, longterm options and challenges for R\&D

3 Stefan Bringezu

\section{Summary}

6 The current flow of carbon for the production, use and waste management of polymer based

7 products is still mostly linear from lithosphere to atmosphere with rather low rates of material recycling. In view of future limited supply from biomass, the article outlines the options to further develop carbon recycling (C-REC). The focus is on carbon dioxide capture and use for the synthesis of platform chemicals to produce polymers. $\mathrm{CO}_{2}$ may be captured from exhaust gases after combustion or fermentation of waste in order to establish a technosphere internal C-REC. As long-term option, an external C-REC can be developed by capturing atmospheric which is increasingly being used for storage and transport of energy, but may also be used for renewable carbon supply for chemistry. The energy input for the C-REC processes can come from wind and solar systems, in particular power for the production of hydrogen which is combined with $\mathrm{CO}_{2}$ to produce various hydrocarbons. Most of the technological components for the system do already exist, and first modules for renewable fuel and heating systems are underway in Germany. The article outlines how the system may further develop on the medium to long term, from a piggy back ad-on flow system towards a self-carrying recycling system which has the potential to provide the material and energy backbone of future societies. A critical bottleneck seems to be the capacity of renewable energy supply rather than the costs of carbon capture.

24 Key words: $\mathrm{CO}_{2}$ as raw material, polymers, green chemistry, carbon capture and (re-)use, 
2 This article aims to outline carbon recycling which makes use of $\mathrm{CO}_{2}$ as raw material. In

3 recent years, anthropogenic emissions of $\mathrm{CO}_{2}$ have been recognized as key driver of climate

4 change, a burden which one should better get rid of. While this is still true, the long-term

5 development of the material and energy basis of societies may reward to think not only about

6 those carbon flows which should be reduced, but also those which ought to be continued or

7 even need to become established as the future backbone of the socio-industrial metabolism.

8 With a view of the massive carbon flows released in particular from the incineration of fossil

9 energy carriers, carbon capture and storage (CCS) draw special attention with the IPCC

10 (2005) report. Subsequently, also the risks and uncertainties as well as issues of long-term

11 liabilty associated with that approach came closer to scrutiny (Wilson et al. 2007). Seven

12 years after the IPCC special report, Khesghi et al. (2012) in their review observed that climate

13 policies in many parts of the world did not materialize, leading to low incentives for CCS,

14 that costs of CCS in general were higher than initially estimated, and public acceptance turned 15 out to be a major obstacle.

16 Instead of putting $\mathrm{CO}_{2}$ away, one can try to make use of it. Worldwide, the major use of 17 technical $\mathrm{CO}_{2}$ today is for enhanced oil recovery (EOR) in particular in North America and 18 for urea production (PB and GCCSI 2011). In particular EOR may be regarded as special 19 form of CCS, as there is no further use of the substance after injection into the ground.

20 Carbon capture and use (CCU) goes further than CCS. Styring et al. (2011) describe the use 21 of $\mathrm{CO}_{2}$ to manufacture fuels, chemicals and materials. They define $\mathrm{CCU}$ as "as a process 
1 whereby the $\mathrm{CO}_{2}$ molecule ends up in a new molecule". Although this distinguishes the use

2 from simple underground deposition, the transformation of $\mathrm{CO}_{2}$ into new chemical

3 compounds does not guarantuee a further use of the resulting materials. And it is the use

4 which will determine where and when the molecule will finally end up.

5 This article will focus on the use of $\mathrm{CO}_{2}$ as raw material for polymers and how this use can be

6 further developed towards an economy-wide cycle. Polymers comprise a variety of chemical

7 compounds which provide base materials with a wide range of technical properties (Ravve

8 2012). Although some applications such as packagings are rather short lived, others such as

9 for pipes, window frames, wall insulations have a long durability which provides also the

10 option of a certain amount of carbon storage within the technosphere. While polymers

11 currently represent only a relative small portion of all materials used, the future technological

12 development may lead to a much higher proportion of carbon based products. In 2011, global

13 plastics production amounted about $280 \mathrm{MMt}$ with one fith produced and one sixth consumed

14 in Europe (PEMRG 2012). The biggest end-use applications were packaging (39\%), building

15 and construction (20\%), automotive (8\%), and electrical and electronic equipment (5\%). Out

16 of 25.1 MMt plastics which ended up in the waste stream, $25 \%$ were recycled, $34 \%$ collected

17 for energy recovery and $41 \%$ were landfilled, with high variations between countries

18 depending on their waste management schemes. Recycling rates vary mostly between 15 to

$1930 \%$, whereas energy recovery rate ranges from 0 to $75 \%$.

20 Polymers such as polyethylene, polypropylen, polyurethane, polystyrene consist mainly of a

21 carbon structure, with hydrogen as energy backpack in the molecule. So far, they are

22 produced mainly from petroleum and partly also from natural gas and coal. In recent years,

23 polymers have also been developed on the basis of biomass, e.g. for food packaging (Gurgel 
1 et al. 2011), often with the intention to increase renewability and biodegradability (Averous

2 and Pollet 2012, Siracusa 2008). As biomaterials may have similar side-effects like biofuels,

3 such as competition for land (Weiß et al. 2012), this article will explore options of renewable

4 material supply which are more independant from agriculture and forestry.

5 One key challenge is to make better use of $\mathrm{CO}_{2}$. Chemists have already developed a multitude

6 of processes which use $\mathrm{CO}_{2}$ as input and carbon source to produce fuels and base materials

7 (for review see $\mathrm{Hu}$ et al. 2013, Rayner 2007). Chemical associations like those based in the

8 USA (Rittner 2007) and Germany (VCI and DECHEMA 2009) have taken up the challenge

9 to enhance research towards this end. The German ministry for science and education in 2011

10 launched a 100 million $€$ research program to explore and further develop the various

11 technologies to use $\mathrm{CO}_{2}$ as raw material ${ }^{1}$.

12 So far, the use of $\mathrm{CO}_{2}$ as technical gas for synthesis is still associated with a net release of 13 green house gas emission, due to the energy consumption for those processes and the energy

14 supply which basically comes from fossil sources ${ }^{2}$. Thus, whether the use of $\mathrm{CO}_{2}$ as raw

15 material will contribute to the mitigation of the climate change problem will depend on the

16 development of new technologies with a favourable life-cycle-wide balance.

17 When $\mathrm{CO}_{2}$ is used as raw material, this requires energy. In order activate the carbon atom for

18 chemical reaction and energy storage, often a combination with hydrogen is used, and

19 hydrocarbons are the form of compounds which act as integrated carbon and energy carriers.

20 The recycling of hydrocarbons has so far mainly been discussed in the context of the so-called

1 interim results see: www.fona.de/en/8863 [accessed 27 May 2013]

2 presentation of Friedrich Seitz, President Process Research \& Chemical Engineering, BASF, at the bmbf

Status Conference "Chemische Prozesse \& Stoffliche Nutzung von $\mathrm{CO}_{2}$ ", Berlin, 9 April 2013 
1 hydrogen economy with a focus on the storage of renewable energies. While hydrogen

2 produced by electrolysis could be the primary molecule to chemically store power produced

3 by solar or wind, it is difficult to handle. Therefore, Olah et al. (2009) suggested the

4 "methanol economy". Tranforming hydrogen into methanol would offer the advantage that

5 the existing infrastructure for storage and transport of liquid fuels could be futher used. The

6 main focus has been the generation of renewable fuel for transport, while the authors also

7 acknowledged that methanol is a platform chemical which could be used for the synthesis of 8 chemicals such as polymers.

9 Hydrocarbons have the potential to play a key role in the development of both renewable energy and renewable materials supply. This article will outline a vision of future carbon

11 recycling focussing on the capture and use of $\mathrm{CO}_{2}$ from waste management. It will describe

12 recent developments in particular in Germany with regard to the provision of renewable

13 methane. This SNG may play a key role for storage and transport of both hydrogen (energy)

14 and carbon (material). The article will then discuss those processes which need to be further

15 developed towards a more cascading use of carbon and finally towards a self-carrying carbon 16 recycling driven by renewable energy.

\section{7 <level 1> Status quo: carbon flows for polymer products}

18 Durable and consumable products such as furniture, textiles, storage boxes, window frames, 19 packaging to a large extent are made of natural fibres (wood, cotton with the key component 20 of cellulosis, a natural polymer of glucose) or synthetic polymers ("plastics"). Their carbon 21 constituents are derived from biomass or fossil fuels. Figure 1 sketches a selection of aggregated flows for Germany. 
1 In 2011, in Germany 20.7 MMt of plastics were produced, 11.9 MMt exported, 8.4 MMt

2 imported (Consultic 2012). From the 17.2 MMt total input to manufacturing, 10.6 MMt

3 consisted of the basic polymers (such as PE, PP, PS, PVC, PA), whereas the rest were glues,

4 varnishes, resins, fibres and so forth. Considering that one third of German industry

5 production is for export, and assuming this holds also for plastic based final products, that

6 would render 7.1 MMt polymers for domestic final consumption. Assuming an average

7 carbon content of about $75 \%$, and neglecting production losses, one would need about 5.3

8 MMt carbon as source to produce this amount. As 1.4 MMt post-consumer plastic waste was

9 recycled, at least $4 \mathrm{MMt}$ of fossil carbon would be required to supply the domestic demand.

10 While a complete and detailed carbon flow analysis for Germany is still lacking, the available

11 data indicate that the use of biomass based products is much higher than that of synthetic

12 polymers. For instance, about $20 \mathrm{MMt}$ of paper and board ${ }^{3}$ are consumed annually of which

13 three quarters are recycled material (VDP 2013). Furniture and textiles often comprise both

14 biomass and fossil based carbon compounds, and they may be stocked in households and

15 offices for a longer period of time.

3 of which about $35-45 \%$ is carbon content 


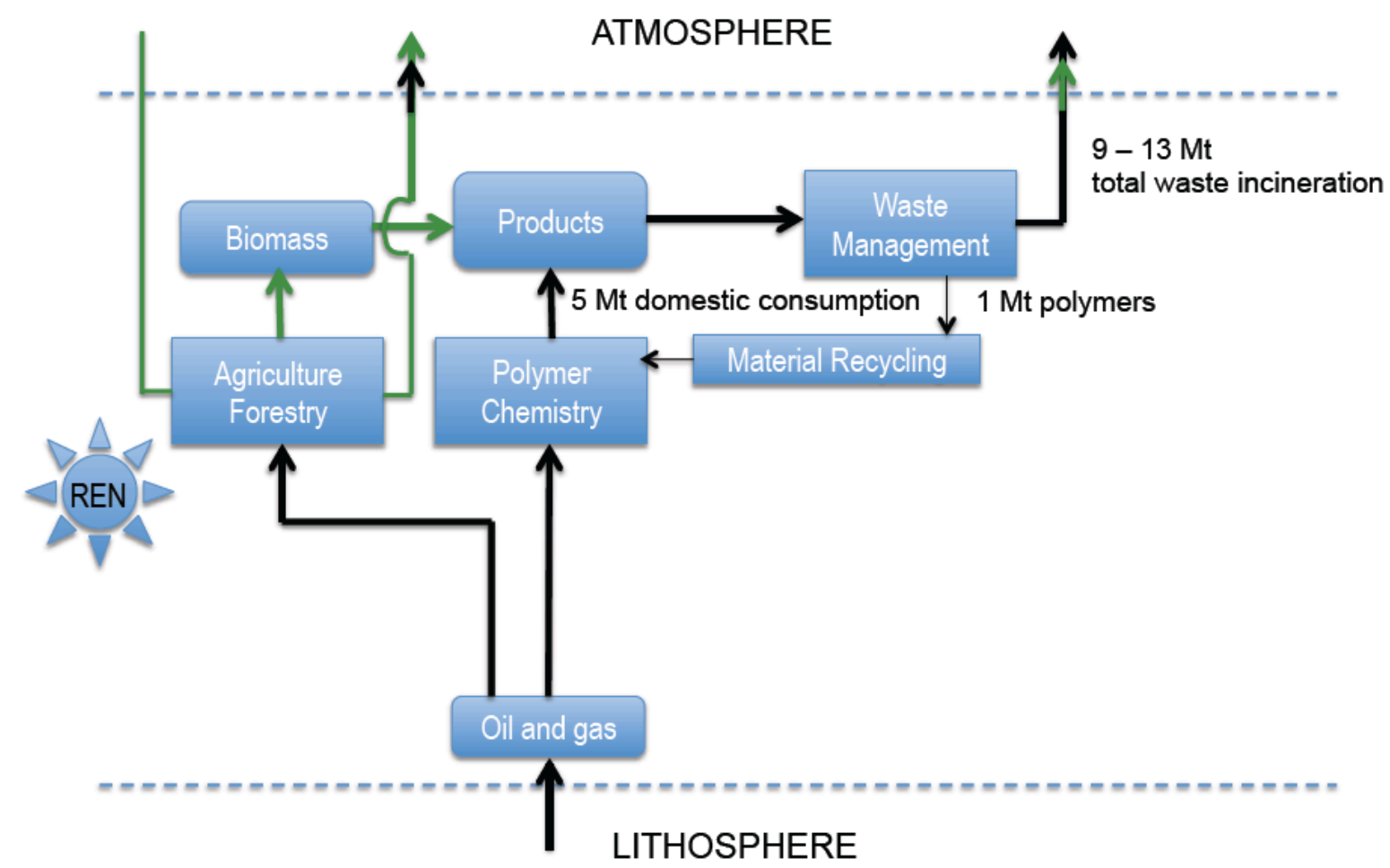

2 Figure 1. Simplified scheme of carbon flows of non-food products with selected data for

3 Germany 2011.

4 Although there is a growing demand for non-food biomass based products, in the form of

5 biofuels and biomaterials, there are indications that the consumption level of agricultural

6 products in the EU may have exceeded a safe and fair level (Bringezu et al. 2012), and a

7 similar tendency can be found for countries such as Switzerland (Zah et al. 2010), which,

8 altough rich in forests, is going to consume over average net annual increment of global

9 forests. In any case, product consumption in Germany is on the way of getting more

10 dependant from natural resources in other countries and non-EU regions.

11 If neither agriculture nor forestry may be expected to increase their supply of carbon materials

12 for non-food purposes without shifting problems to other regions, and if the use of fossil fuels 
1 for products which are finally incinerated and end up in $\mathrm{CO}_{2}$ emissions shall also be reduced,

2 where shall the carbon resource base for the future come from?

3 This leads to a closer look at a potential resource: the emissions of $\mathrm{CO}_{2}$ from waste

4 management. Since June 2005, Germany has practically banned organic waste from

5 landfilling. It needs to be pretreated in order to guarantuee that landfills receive only mineral

6 constituents. As a consequence, most of organic, carbon material based waste is incinerated.

7 In 2011, in Germany 24.4 MMt waste went to thermal waste treatment plants and 19.7 MMt

8 became input of incineration plants with thermal recovery (DESTATIS 2013). This covers co-

9 incineration but also specific plants for fuels derived from residues.

10 The carbon content of the waste going to incineration varies between $0.209 \mathrm{~kg} \mathrm{C} / \mathrm{kg}$

11 freshweight for household waste and $0.355 \mathrm{~kg} \mathrm{C} / \mathrm{kg}$ freshweight for bulky waste (Bilitweski

12 2006). For wooden residues incinerated for instance in carpenters'workshops the value may

13 be even higher. Assuming a range of $0.2-0.3 \mathrm{~kg} \mathrm{C} / \mathrm{kg}$ freshweight, the emissions from the

14 incineration of waste would be in the range of $32-48 \mathrm{MMt} \mathrm{CO}_{2}(=8.8-13.2 \mathrm{MMt} \mathrm{C})$ in

15 Germany in 2011. Based on latest data for total $\mathrm{CO}_{2}$ emissions in Germany for 2010 (813.5

$16 \mathrm{MMt}$ ) this would be $4-6 \%$.

17 <level 1> A possible future system of carbon recycling

18 The status quo can be further developed by increased recycling of carbon. Following a

19 sequence of widening circles, different options may be pursued: 
1. increased separate collection and recycling of specific waste types, including different types of polymers for material specific recycling;

2. processing of mixed waste fractions for chemical synthesis (e.g. by gasification of dry organic waste to produce syngas, and fermentation of wet organic waste to produce biogas; both of which can be used not only for energetic purposes but also for the production of platform chemicals from which various types of polymers can be generated).

3. capturing $\mathrm{CO}_{2}$ after incineration or after fermentation from biogas cleaning and further use as raw material for chemical synthesis.

The first strategy is already implemented to a certain degree in Germany and other European countries (ACRR 2004). It will probably be continued for those waste fractions, collections systems and recycling technologies which offer economic and environmental benefits. As it is rather well established, it will not be further discussed here. The second strategy will be shortly reviewed below with regard to implementation. The focus of this article is on the third strategy, in particular on capture of $\mathrm{CO}_{2}$ from the exhaust gases of incineration and subsequent processing.

The captured $\mathrm{CO}_{2}$ can be combined with $\mathrm{H}_{2}$ to methane, $\mathrm{CH}_{4}$, the most energy rich hydrocarbon molecule, for instance, in the Sabatier process: $\mathrm{CO}_{2}+4 \mathrm{H}_{2}-->\mathrm{CH}_{4}+2 \mathrm{H}_{2} \mathrm{O}$. On the long run, the provision of the hydrogen would only be sustainable if derived from renewable power from wind or solar. The power can be used for electrolysis: $2 \mathrm{H}_{2} \mathrm{O}+$ energy $->2 \mathrm{H}_{2}+\mathrm{O}_{2}$. The hydrogen within hydrocarbon compounds provides the stored energy required to drive the cycle and to keep the carbon in a chemically reduced form, in other words to avoid oxidization and release to the atmosphere. Following this route, the principle 
1 of carbon capture and use (CCU) can be implemented, more precisely carbon capture and re-

2 use (CCR). In this article the term carbon recycling (C-REC) is used.

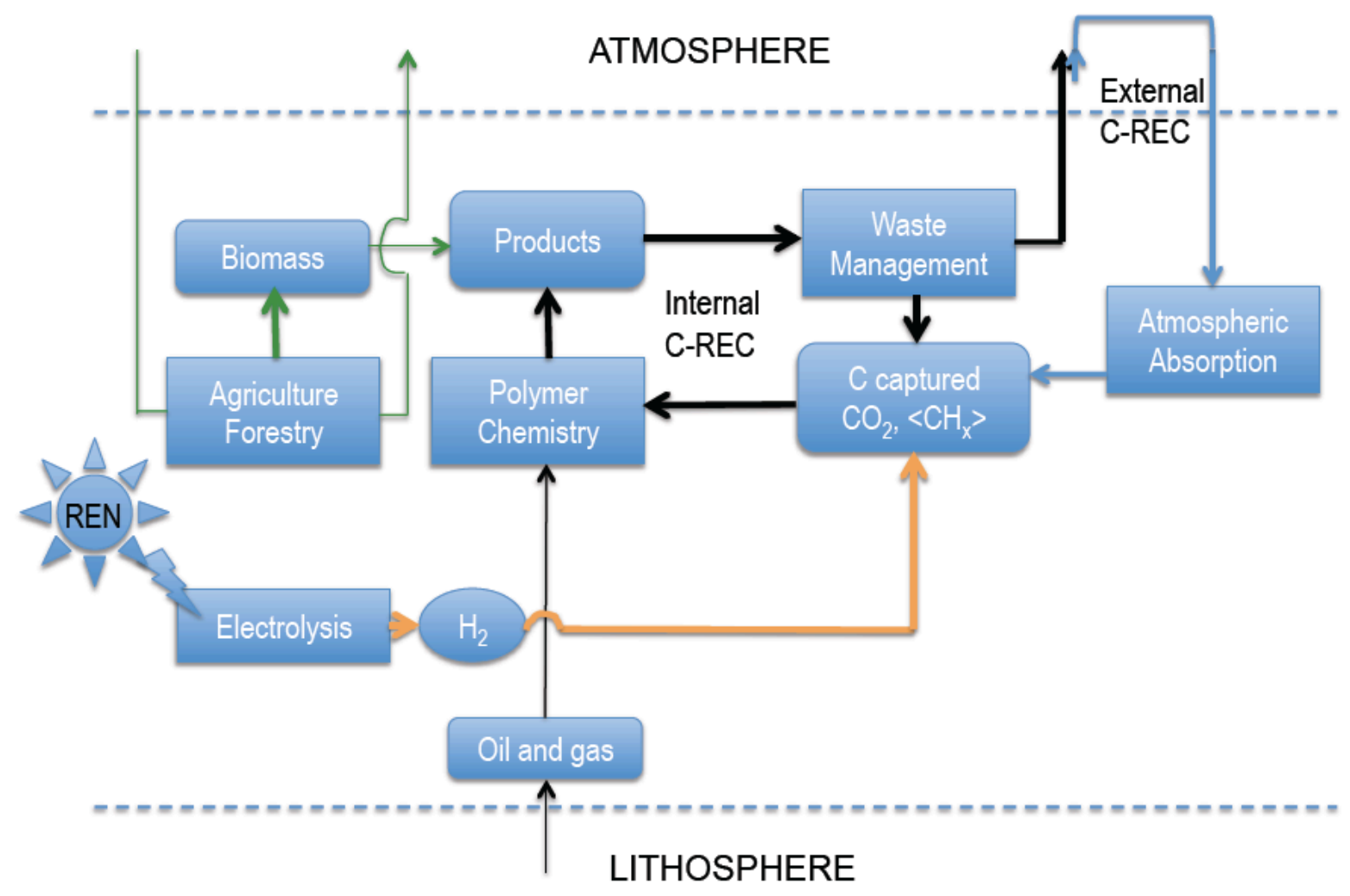

4 Figure 2. Scheme of a potential C-REC system driven by renewable hydrogen. Simplified 5 scheme, explanation see text.

6 Capturing and using carbon from waste would establish a C-REC within the technosphere

7 ("Internal C-REC"). Alternatively, also an external C-REC will be possible, if $\mathrm{CO}_{2}$ is

8 absorbed from ambient air (Lackner 2009). Then organic wastes or fuels could be further

9 incinerated or fermented or otherwise oxidized and released at any place, and the cycle would

10 be closed via the atmosphere. 
1 As an interim step toward this recycling scheme, a more cascading use of carbon within the

2 technosphere is also possible. As a carbon source for the methanation, $\mathrm{CO}_{2}$ can be captured

3 from fossil fuel fired power or heating plants, steel blast furnaces or cement kilns. Their

4 carbon flow which stems from the litosphere would finally also end up in the atmosphere,

5 however, the ad-on processes would allow to keep it longer in use and thus retard GHG

$6 \quad$ emissions (also by substituting for fossil and biomass based products).

\section{$7 \quad<$ level $1>$ Realization and challenges of carbon recycling}

8 Nearly all technological components required for the full C-REC system do already exist,

9 although in different contexts. Some milestones are in preparation with a focus on the storage

10 and transport of renewable energy. For the example of Germany, Figure 3 indicates the

11 processes which have been or are going to be established shortly and those connections which

12 are still lacking and would need to be further developed for C-REC.

$<$ level 2> Windgas for energy storage and transport

14 In Germany, an extended pipeline and storage system for natural gas exists. The underground

15 storage contains more than 20 billion $\mathrm{m}^{3}$, which provides about the amount consumed in

16 Germany within a quarter of a year, and in addition, there are pipelines with around 475.000

$17 \mathrm{~km}$ (BDEW 2012). In the North and Northwest of Germany, onshore and offshore wind

18 energy parks are providing significant power supply. Sterner et al. (2011) suggested to store

19 peak power which is not directly consumed in the form of "wind gas" (or "power-to-gas"),

20 that is to electrolyse water and methanize the resulting hydrogen. The methanation can even

21 be spared by feeding hydrogen directly into the natural gas pipeline system, which is in

22 compliance with the German standards possible up to 10\% (Müller-Syring et al. 2011). 
4 Figure 3. Status quo of material flows in Germany (black and green for fossil and biomass

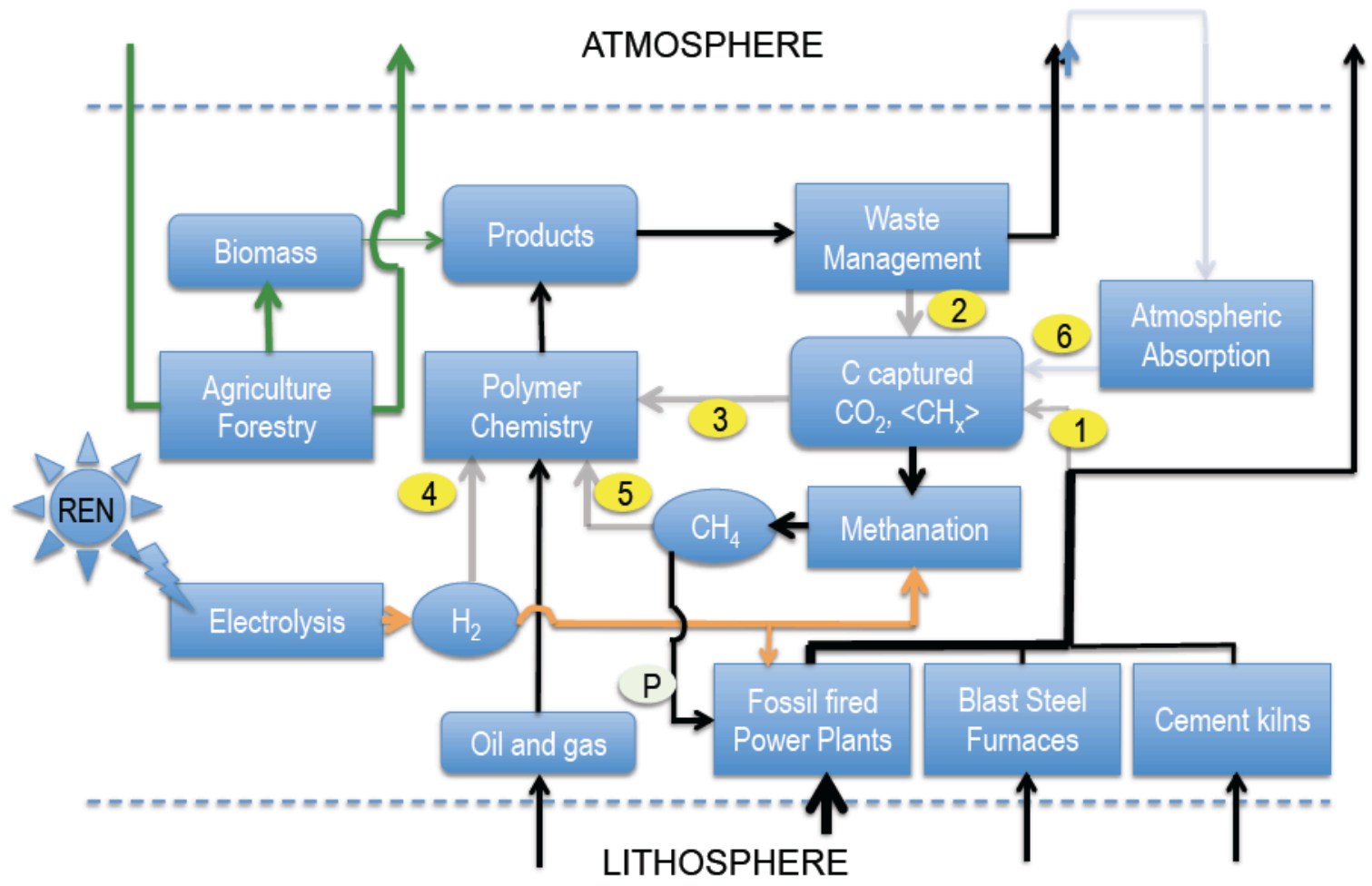

6 The hydrogen feed-in is planned to start summer 2013, for instance, by Greenpeace Energy,

7 an energy supply company where clients then can buy renewable gas for their homes ${ }^{4}$. A first

8 methanation plant, with $250 \mathrm{~kW}_{\mathrm{el}}$, has been developed by the Center for Solar Energy and

9 Hydrogen Research (ZSW), the Fraunhofer Institute for Wind Energy and Energy System

10 Technology (IWES) and the SolarFuel company in Stuttgart (the ongoing research project

11 lasts until 2014) $)^{5}$. Based on this experience, a methanation plant with $20 \mathrm{MW}$ capacity is

12 being constructed in Werlte near the city of Bremen where $\mathrm{CO}_{2}$ is taken from the cleaning of

13 biogas which is produced from waste at the premises of the local energy supply company

4 www.greenpeace-energy.de/windgas.html [accessed 16May2013]

5 www.zsw-bw.de/fileadmin/editor/doc/20111019_Power-to-Gas_Projektinfo_01.pdf [accessed 16May2013] 
1 EWE. The facility provides socalled e-gas for the Audi motor company and its planned A3

2 Sportback TCNG car and can generate renewable synthetic natural gas to fuel 1500 TCNG

3 vehicles with 15000 kilometers a year (2012).

4 The power-to-gas technology is being explored mainly with a focus to store renewable energy, and project developers so far tend to use $\mathrm{CO}_{2}$ from biogas as carbon source for methanation $^{6}$ and hydrogen may also be directly mixed with biogas ${ }^{7}$. Although these pilot plants might provide very useful insights into the options of $\mathrm{CO}_{2}$ capture, methanation, and hydrogen storage, biogas as a carbon source may prove only sustainable if derived from (wet) waste and sewage. In Germany, so far, the majority of biogas plants are fed by maize which is specifically grown for the primary purpose of energy production. In 2011, about 0.9 Mha were used for this purpose (Umweltbundesamt 2013), which is 5\% of the total agricultural area. Before the background that the EU and Germany are net importers of land for their agricultural consumption, and that the global use of cropland would need to be reduced by

14 about one third to reach a level which would allow production to approach a more safe 15 operating space (Bringezu et al. 2012), such an extended use of energy plants might be regarded as nonsustainable in the medium to long term.

17 Thus, one critical question for the further development of C-REC for sustainable energy supply and storage is what carbon source will be available on the long run for methanation.

19 Theoretically, gas based power and CHP supply could become essentially free of GHG 20 emissions: (a) solar and wind, the latter in particular in the North of Germany, could provide 21 electricity for direct use, - which would need to be transported by additional power lines,

6 see for instance, pilot plant development on the conversion area of Moorbach in the Hunsrück region, formerly the largest ammunition depot of the US airforce in Europe, www.energielandschaft.de/energie/stromspeicherung/ [accessed 16 May 2013] 
1 currently in planning and under construction also for direct current - to the South. (b) During

2 times when power supply exceeds direct demand, the electricity would be stored in the form

3 of hydrogen, which would be methanized, and the methane fed into the pipeline system for

4 storage and transport to the South. There, central power and CHP plants with a high energy

5 efficiency would incinerate the methane in times of peak demand. If the resulting $\mathrm{CO}_{2}$ were

6 captured and transported to the methanation plants (route 1-P in Fig. 3), the carbon cycle

7 could be closed. However, that would require a double pipeline to get the $\mathrm{CO}_{2}$ to the North (a

8 triple line transporting pure oxygen from the hydrolysis in the North to the power plant in the

9 South would guarantee nearly purified $\mathrm{CO}_{2}$ as process outlet of the power plant). Irrespective

10 of the investment costs which could prove prohibitive, also safety precautions may hinder

11 such a development. For instance, local protests against a $\mathrm{CO}_{2}$ pipeline in the context of CCS

12 from a lignite power plant in Hürth near Cologne over $600 \mathrm{~km}$ to Schleswig-Holstein to

13 deposit the $\mathrm{CO}_{2}$ in underground caverns were stirred by a fatal $\mathrm{CO}_{2}$ accident with more than

14100 people injured ${ }^{8}$. The debate on the uncertainties of CCS had contributed to the tightening

15 of governmental support and finally lead the power company RWE cancel the pipeline plans ${ }^{9}$.

16 Alternatively, route 1 could originate from $\mathrm{CO}_{2}$ emitted from other fossil fired power or CHP

17 plants, or blast steel furnaces or cement kilns in the vicinity of the methanation plant. In fact,

18 RWE tests the power-to-gas technology at the coal fired power plant Niederaußem, west of

19 Cologne, with a PEM electrolysis developed by Siemens in the research project CO2RRECT

20 supported by the German ministry for science and education. The aim is to store peak supply

21 of wind and solar power by hydrogen, which will later be methanized with $\mathrm{CO}_{2}$ captured from

\footnotetext{
7 see for instance, hybrid power plant of ENERTRAG in Prenzlau which is located between Berlin and the Baltic Sea; www.enertrag.com/projektentwicklung/hybridkraftwerk.html [accessed 16 May 2013]

8 www.n-tv.de/wirtschaft/meldungen/RWE-plant-CO2-Pipeline-article19752.html [accessed 16May2013]

9 www.rwe.com/web/cms/en/2688/rwe/innovation/projects-technologies/power-generation/fossil-fired-powerplants/igcc-ccs-power-plant/ [accessed 16May2013]
} 
1 the power plant exhaust gas ${ }^{10}$. Carbon capture is already installed and used to feed chemical 2 synthesis.

3 The carbon captured at the power plant in Niederaußem is used by the Bayer chemical

4 company as feed for a newly developed production of polyurethane which used for the

5 production of mattrasses. This "dream product" shall be put on the market with about one fith

6 to one quarter of the carbon from capture, and is expected to provide improved technical

7 properties, a positive GHG and economic performance compared to $100 \%$ petroleum based

8 polyurethane ${ }^{11}$.

$9 \quad<$ level 2> A potential role for waste management

10 Another potential source of carbon could come from waste management (route 2). The C-

11 REC from waste can generally follow three main paths (for i and ii more details see Hayes

12 2009):

13 (i) Thermochemical routes: In particular dry organic waste such as wooden residues can be

14 (A) gasified by high temperatures and transformed into syngas $\left(\mathrm{CO}+\mathrm{H}_{2}\right)$ which may be (a)

15 converted to methanol, or (b) processed via Fischer-Tropsch synthesis (FTS) to naphtha. Both

16 methanol and naphtha are platform chemicals which can be used to produce olefines (such as

17 ethylene, propylene) and thus provide the basis for polymers. FTS had originally been

18 developed to produce chemicals and transport fuels from coal. In recent years, FTS has been

19 piloted in BtL plants to produce biodiesel from wood, although no plant has become

10 http://www.cleanthinking.de/energiewende-siemens-und-rwe-mit-neuer-elektrolyse-technik-zurstromspeicherung/ (accessed 05/o5/2013)

11 presentations of both Frank Grunert and Oliver Schlüter at the bmbf Status Konferenz Chemische Prozesse \& Stoffliche Nutzung von $\mathrm{CO}_{2}, 9$ April 2013, Berlin 
1 commercial yet. The organic waste can be (B) treated at somewhat lower temperatures by

2 pyrolysis to generate a "slurry" or pyrolysis oil, a mixture of hydrocarbons, which can be transported to refineries where the slurry can be used as substitute for petroleum fractions and generate similar products as of naphtha. Research aiming to produce biofuels on this route from primary wooden material is ongoing at the Karlsruhe Institute of Technology (Dahmen et al. 2012). Gasification of municipal waste was developed by Thermoselect beginning of the 1990s in Fondotoce at the Lago Maggiore in Italy; in Germany it was tested a decade later in

8 Karlsruhe (Themelis 2007) but stopped in 2004 for economic reasons ${ }^{12}$. In Japan, a few more

9 Thermoselect plants were established (Sumio et al. 2004). The main purpose had been the safe treatment of the waste, low emissions of hazardous substances, the minimisation of final

11 solid waste deposition, and energy recovery. Although the possibility was seen to use the 12 syngas also for synthetic purposes, this option was not further pursued. New options may arise when current waste incinerators will have to be replaced, in particular in regions with close chemical industry, like in the Ruhr, in order to establish the routes 2 and 3.

15 (ii) Biochemical routes: In particular wet organic waste, also sewage and sewage sludge, can be processed by acid or enzymatic hydrolysis in order to break up cellulosis and hemicellulosis in to sugar momers and ferment them into various possible acids which can be used for polymer production (e.g. Poly-Lactic-Acid, PLA, or polyurethane); or the wet organic waste is treated anaerobically to generate methane; the latter is mostly used for power and CHP, however, it could also be processed by oxidative coupling into olefines.

(iii) Post-combustion carbon capture: after incineration, the resulting $\mathrm{CO}_{2}$ can be captured by scrubbing with alkaline substances. The technology has been used so far only for coal and gas 
1 fired power plants with mono-ethanol-amine or an aminoacid salt (Siemens ${ }^{13}$ ). Although

2 household waste is chemically even more heterogenous than lignite or hard coal, one may

3 assume that carbon capture could possibly work also with municipal solid waste, in particular,

4 with high caloric (carbon) content. Still further testing would seem adequate, for instance, to

5 check whether fluorides or NOx compounds do not interfer substantially with the capture

6 process. If implemented, waste managing companies may sell the resulting $\mathrm{CO}_{2}$ as feed for

7 methanation which could supply both power plants and chemical industry with renewable 8 SNG.

9 While the generation of waste may be expected to decline somewhat in the coming decades,

10 one may assume an order of magnitude of $10 \mathrm{MMt} \mathrm{C}$ as maximum potential from carbon

11 capture and use from waste incineration in Germany (Figure 1). The potential demand for

12 carbon may be derived from the production and use of plastics. Theoretically neglecting

13 process losses, capturing about half of the total $\mathrm{CO}_{2}$ from German waste incineration and

14 using it as carbon source for polymer production could completely supply domestic

15 consumption, and about three quarters of domestic manufacturing of basic polymers (for

16 volumes as of 2011).

17 German waste management has already established plastic material recycling. In 2011, 1.4

18 MMt post-consumer plastic waste was recycled as base material ("werkstofflich"), this is by

19 keeping the sort of polymer (Consultic 2012). Breaking the polymers down to the carbon

20 source ("rohstoffliches Recycling") was only practised for $53 \mathrm{kt}$. Thus, from the 10.6 MMt of

21 yearly production, already $13 \%$ can be provided by material recycling.

13 http://www.energy.siemens.com/hq/en/power-generation/power-plants/carbon-capture-solutions/postcombustion-carbon-capture/ [accessed 25. Feb 2013] 
1 However, the dominant part of post-consumer plastic waste, altogether $2.9 \mathrm{MMt}$, were

2 incinerated (with energy recovery). Taking the resulting $\mathrm{CO}_{2}$ as carbon source, could - in

3 addition to the established material recycling - potentially supply a quarter of domestic

4 polymer production. When also biogenic organic waste from kitchens and old furnitures

5 would be taken as input for the production of base chemicals, this could further contribute to a

6 more closed internal C-REC. Then, losses in the technical production and during consumption

7 would be refilled by carbon from food and fibres derived from agriculture and from wood

8 derived from forestry.

$9<$ level 2> Versatile use of methane: energy and carbon carrier

10 Regenerated Methane, or SNG, could play a key role in the energy and material supply

11 system. In 2011, there have been already 880 gas stations in Germany to supply 90000 cars,

12 which are $0.2 \%$ of the car fleet (Dena 2011). So far, these are mainly supplied with fossil

13 natural gas. The infrastructure could be further used and widened, the car technology for gas-

14 fired motors is state-of-the-art. In the future, SNG could be provided with no net input of

15 fossil carbon, based on C-REC.

16 Methane may not only be used as energy carrier, for power/heat and transport, but also for

17 material synthesis, as indicated by route 5. Research is ongoing in particular to find

18 appropriate catalysts for targeted transformations. For instance, methane can be oxidized to

19 provide methanol (Soorholtz et al. 2013), an important platform chemical from which acetic

20 acid, formaldehyde and olefines (ethylene, propylene) can be produced. Methane may also be

21 coupled to provide ethylene (Stünkel et al. 2012). Research is also ongoing on dry reforming 
1 of methane with $\mathrm{CO}_{2}$ to produce dimethylether (DME) which is used as platform chemical

2 and can be used as substitute for LPG or diesel ${ }^{14}$.

$3<$ level 2> Various options of hydrogenation of $\mathrm{CO}_{2}$

4 Besides methane, also other platform chemicals can be provided from $\mathrm{CO}_{2}$. Each of these

5 transformations, however, also requires energy, either for the provision of hydrogen or direct

6 reduction with electricity. For instance, both BASF and Bayer are working on hydrogenation

7 of $\mathrm{CO}_{2}$ to produce formic acid, and research is ongoing on the production of hydrogen

8 cyanide from $\mathrm{CO}_{2}{ }^{15}$. While the experiments are still based on conventional sources of $\mathrm{CO}_{2}$, in

9 the future, those technologies could become part of the C-REC route 2-3/4 (Figure 3).

<level 1> Discussing development options under sustainability aspects

11 Starting from status quo, which differs significantly between countries, the question arizes

12 which routes of carbon processing should be developed with priority, while considering

13 technological feasibility and metabolic sustainability. Certainly, economic aspects, in

14 particular the competition with fossil oil, gas and coal will play an important role. From a strategic point of view it seems necessary to look for long-term options and potential limitations of business-as-usual, because if investments which under current conditions seem

17 promising will turn out as dead end in a decade or two due to inconsistency with meta-

18 metabolic developments and sustainability conditions, then at the latest, the question will be

19 how such sunk costs could have been avoided.

\footnotetext{
14 www.chemieundco2.de/_media/28_DMEEXCO2.pdf [accessed 17 May 2013]

15 presentations of Friedrich Seitz and Ekkehard Schwab, BASF, and Oliver Schlüter, at the bmbf Status Conference "Chemische Prozesse \& Stoffliche Nutzung von $\mathrm{CO}_{2}$ ", Berlin, 9 April 2013
} 
1 The long-term development of the socio-industrial metabolism may be expected to follow a

2 maturation path towards a system with a high degree of internal material flows and recycling

3 which is largely driven by renewable energy such as solar (Graedel and Allenby 1995), a

4 situation which is known from complex natural ecosystems (Odum 1959). Operational criteria

5 and indicators for a more sustainable metabolism of the European Union have been discussed

6 elsewhere more extensively (Bringezu 2009, 2013). In general, the conditions comprise: (1)

7 the material supply is largely based on recycling within the anthroposphere, (2) the energy

8 supply is mainly derived from renewable energies such as solar and wind, (3) the remaining

9 inputs from and outputs to the enviroment do not exceed levels of safe operating space, and

10 (4) the physical growth of the anthroposphere is limited accordingly. The outline of the C-

11 REC system is in line with the criteria (1), (2) and (3) and its implementation might contribute

12 to sustaining the socio-industrial metabolism by substituting a recycling and/or more

13 cascading use of carbon compounds for a linear, fast throughput system, the integration of

14 renewable energy supply, storage and transport, and the mitigation of green house gas

15 emissions to the atmosphere. With regard to long-term dynamics of the metabolism, the

16 question remains which carbon sources will be available under future conditions of both

17 sustainable material and energy supply.

18 The carbon recycling routes may be distinguished according to their basic metabolic

19 characteristics (Table 1).

20 (I) In those cases when carbon would be extracted from exhaust gases from fossil fired power

21 plants, cement kilns or blast furnaces, and combined with hydrogen to produce synthetic

22 natural gas, the carbon would be used as interim hydrogen carrier ("piggy back" system). The

23 amount of carbon captured would balance the amount of carbon released during subsequent 
1 incineration processes ("C in $\mathrm{C}$ out"). In that sense, the synthesized methane would be

2 renewable SNG. As carbon capture and release would usually happen at different locations, a

3 quasi-cycle would be established. In few cases, when gas fired power stations would run only

4 for peak power demand with methane regenerated during peak renewable power supply on

5 the same spot, even a closed cycle could be established. The use of renewable SNG would

6 substitute fossil energy carriers and thus contribute to mitigate atmospheric emissions. In any

7 case, the methane would (only) serve as for transport and storage of renewable energy.

8 Table 1. Metabolic charateristics of carbon routes as shown in Figure 3.

\begin{tabular}{|l|l|l|l|l|}
\hline & Possible Routes & Terminology & Purpose & C flow system \\
\hline I & $1-\mathrm{P}$ & renewable SNG & energy transport & quasi cycle \\
and storage & (C-in C-out) \\
\hline II & $1-3 / 4$ or $1-5$ & "waste $\mathrm{CO}_{2}$ as raw material" & hydrocarbon & cascade $(\mathrm{CCU}$ \\
\hline III & $2-3 / 4$ or $2-5$ & Internal carbon recycling & hydrocarbon & real cycle \\
& & & supply and reuse & possible \\
\hline IV & $6-5$ or $6-3 / 4$ & External carbon recycling & hydrocarbon & real cycle \\
& & & supply and reuse & possible \\
\hline V & $6-P$ & External carbon recycling & energy transport & real cycle \\
& & & and storage & possible \\
\hline
\end{tabular}

9

10 (II) The carbon captured from fossil sources may also be used for the synthesis of materials,

11 in particular polymers by chemical industry. For that purpose, the $\mathrm{CO}_{2}$ would be reduced, for

12 instance by combination with hydrogen or hydrogenated compounds. One possible route 
1 would go via methane, and renewable SNG may also be a feed-stock for chemical industry.

2 Like in case I, this may substitute for the original petroleum or natural gas basis of

3 conventional polymers. Still, however, the carbon system would be an open cascade and not

4 yet a cycle.

5 (III) If, in contrast, the carbon would be extracted from waste and converted into useful

6 hydrocarbons, a full cycle within the technosphere could be established. So far, recycling of

7 organic materials is well established for selected materials such as paper and board, and base

8 polymers such as polyethylene and polypropylene, where only the fractions which become

9 too mixed or are no longer viable for material recycling are incinerated for recovering the energy content. Thermal treatment, in particular complete oxidization by incineration, has the

11 advantage to destroy the chemical structure of organic molecules and eliminate undesirable

12 compounds. The carbon content, nevertheless, can provide a useful basis for recycling also

13 via $\mathrm{CO}_{2}$ and $\mathrm{CH}_{4}$. Establishing internal $\mathrm{C}$-REC will require also transport of the carbon

14 captured in waste management facilities either directly to chemical industry, for instance in

15 the form of pyrolysis slurry, or as $\mathrm{CO}_{2}$ gas, or indirectly via SNG. If the latter is produced by

16 methanation next to the carbon capture, either the required hydrogen or the power for

17 electrolysis will need to get there. As hydrogen pipelines are hazardous, long-distance

18 transport may better use the electricity net.

19 (IV and V) A long-term option might be the establishment of external or open-loop C-REC as

20 soon as $\mathrm{CO}_{2}$ can be captured from ambient air under reasonable conditions. Current research

21 as conducted by teams like Lacker et al. aims primarily at the provision of renewable

22 transport fuels. Nevertheless, if those technologies can compete successfully with petroleum

23 based fuels, they might also be available for renewable material supply. Still, however, the 
1 plant developed by Lackner $(2009,2010)$ in its pilot version requires $3 \mathrm{~m}^{3}$ of water and $1.1 \mathrm{GJ}$

2 electricity per ton of $\mathrm{CO}_{2}$ captured. Based on the German electricity mix, the power

3 consumption would require even hundred times more water per ton of $\mathrm{CO}_{2}$ captured (for the

4 cooling water of the central power stations). One might assume further improvements in

5 process efficiency, and although the technology seems to work better in arid regions with low

6 air humidity, it also works in cooler regions, and considering the availability of water, the

7 technology would probably be more suited in water rich regions. The power supply would

8 better be based on renewable energy technologies with significant less water and material

9 resources per kWh than the current mix (as would be the case for wind power).

10 Any future technology will have to outcompete status quo systems not only with regard to

11 economic aspects, but also with regard to basic environmental performance and the efficiency

12 in the use of natural resources. For that purpose, key performance indicators can be applied to

13 measure the systems-wide requirements of primary materials (total material requirement),

14 water, land and the emission of green house gases. These indicators can be applied for

15 selected process chains, for infrastructure systems, as well as for whole economies ${ }^{16}$.

16 When reflecting on the development of piggy-back systems, the long-term availability of the

17 carrier system, worldwide trends and local-regional dynamics will have to be considered. For

18 instance, coal fired power plants might not be regarded as long-term sustainable system, and

19 in particular in countries like Germany will be superseded by renewable energy supply

20 systems, possibly in combination with gas/SNG power stations for peak supply. Regarding

21 blast steel furnaces, Paulick et al. (2013) have shown that the world steel market might

22 change dramatically after 2025 when China will shed the world market with scrap steel and 
1 leave many blast furnaces as sunk costs. Regarding cement kilns one may assume that

2 concrete will remain an important base material, however, the dynamics of the construction

3 sector indicate that in regions like Western Europe the stock of buildings and infrastructures

4 are approaching a saturation level. Of course, also under conditions of a steady-stocks-

5 society, there will be a certain input of primary material required to balance the unavoidable

6 losses, however, the level of demand for primary input could be significantly lower than

7 today.

8 Thus, the question arises which flows may be more reliable also under mid- to long-term

9 considerations. This might be waste flows from households and industry. Although current

10 and upcoming efficiency programs may lead to enhanced avoidance of waste generation,

11 there will always be some remaining waste which needs treatment, and in the best of all cases

12 revert the waste into a useful resource.

13 In Germany, already a competition between waste managing companies, private and public

14 ones, is ongoing about the access to various waste streams, in particular to those which are

15 most valuable. There is an overcapacity of waste incinerators so that waste is also imported

16 from other EU countries like Italy. In case, waste managing facilities could earn additional

17 benefit from selling their output as feed for SNG suppliers or chemical industry, this could

18 render them an advantage in the enhanced competition.

19 Some proxy calculations may indicate the challenge from a commercial point of view. When

$20 \mathrm{SNG}$ is produced from captured $\mathrm{CO}_{2}$ and methanised hydrogen which is produced by

16 At the EU level, the so-called dashboard of key indicators for the implementation of the Roadmap for Resource Efficiency comprises territorial and life-cycle-wide (global) input of materials, land, water and output of GHG emissions. 
1 electrolysis with wind power, the order of magnitude of costs can be roughly estimated.

2 Carbon capture from coal fired power plants costs about $30 €^{17}$ per ton $\mathrm{CO}_{2}$ (Zero Emission

3 Platform 2011), which equals $1.3 € / \mathrm{kmol}$. Electrolysis of water with $\mathrm{KOH}$ with commercial

4 installations requires up to about $4.5 \mathrm{kWh} / \mathrm{Nm}^{3}$ of $\mathrm{H}_{2}$. With $0.19 € / \mathrm{kWh}$ wind power -

5 according to feed-in tariffs for German offshore installations - the energy for electrolysis

6 costs $19 € / \mathrm{kmol} \mathrm{H}_{2}$. The enthalpy for the endothermic reaction $\mathrm{H}_{2} \mathrm{O}->\mathrm{H}_{2}+1 / 2 \mathrm{O}_{2}$ is 289.5

$7 \mathrm{~kJ} / \mathrm{mol}$. Under those electricity prices, costs for electrolysis cannot fall below $15 € / \mathrm{kmol} \mathrm{H}_{2}$.

8 The methanation then combines the captured $\mathrm{CO}_{2}$ with the hydrogen from electrolysis: $4 \mathrm{H}_{2}+$

$9 \mathrm{CO}_{2}->\mathrm{CH}_{4}+2 \mathrm{H}_{2} \mathrm{O}$. The reaction is exothermic $(-165 \mathrm{~kJ} / \mathrm{mol})$, but requires higher pressure

10 and temperatures. Research on process integration may help to enhance energy efficiency and

11 reduce the overall energy (and power) reqirement of electrolysis and methanation. Without

12 energy recovery from methanation, and neglecting the costs for the process itself, only the

13 costs for the feed materials would add up to $77 € / \mathrm{kmol} \mathrm{CH}_{4}$ or $4.8 € / \mathrm{kg}$. For comparison, the

14 price of natural gas in the last quarter of 2012 and first quarter of 2013 was around 3

$15 € / \mathrm{mmBtu}$ or $0.16 € / \mathrm{kg}$. Thus, the renewable $\mathrm{SNG}$ would be up to 30times more costly than 16 natural gas. In that bottom-line calculation, the costs for capturing the $\mathrm{CO}_{2}$ would not even 17 matter. With constant off-shore wind power prices, costs could go up to $50 € / \mathrm{tCO}_{2}$ captured, 18 before the overall price relation to natural gas would be affected.

19 While $\mathrm{CO}_{2}$ capturing from municipal waste treatment plants would still have to be developed, 20 one may expect that the costs might range in a similar magnitude like for coal fired power

21 plants, and the estimation shown indicates that there may be even some room to cover 22 additional costs for flue gas cleaning. Nevertheless, the main challenge for developing C-REC 
1 will be to lower the costs for renewable electricity supply, in particular off-shore wind.

2 Bringing down the costs for wind power to $0.10 € / \mathrm{kWh}$ - an order of magnitude which has

3 been reached for onshore wind already - would nearly half the outlined production price of

4 renewable SNG and render the price ratio to natural gas more favourable. Still a factor 17

5 would have to be bridged, probably by price increases of natural gas, either as a consequence

6 of long-term scarcity or political pricing of fossil fuels due to climate and resource policies, or

7 both.

8 Before that background it seems more sensible to use wind power for electrolysis only for

9 periods when peak supply exceeds electricity demand or net capacities. In such a situation the

10 interim storage of the generated power could provide the supply companies with additional

11 revenue, either by reconverting it later to electricity or by selling the chemical storage

12 material in the form of hydrogen of SNG for material synthesis. As the peak power supply

13 would get lost without any use, the costs for using it could be significantly lower than

14 average.

15 Still the question arises about the capacities of renewable power, in particular offshore wind.

16 So far, one pilot wind park, Alpha Ventus, has been established off the German North Sea

17 coast, with $60 \mathrm{MW}$ (12 turbines). Plans foresee the establishment of 20 - $25 \mathrm{GW}$ capacity

18 until $2030^{18}$. Based on the proxy calculations above, without significant incease in the energy

19 efficiency of electroysis and methanation, the whole of that capacity would be required to

20 produce the domestic polymer consumption of Germany as of 2011 based on renewable SNG.

combustion capture

18 Energy strategy of the German government 2011

http://www.bundesregierung.de/Content/DE/StatischeSeiten/Breg/Energiekonzept/1-Energie\%20erzeugen/23-

11-11-wind.html [accessed at 20 May 2013] 
1 This indicates that renewable power supply may constitute an important bottleneck for the

2 establishment of C-REC. At the same time, the German chemical industry is already the

3 largest in Europe, and requires about $12 \%$ of domestic primary energy consumption (power

4 and heat $)^{19}$ and about $7 \%$ of domestic electricity consumption ${ }^{20}$. From the estimates shown

5 above, one may conclude that switching to carbon sources captured from waste management

6 may be less challenging than progressing with the use of renewable energy supply. Both

7 challenges might also be tackled in parallel. In fact, chemical industry has started to use

8 captured $\mathrm{CO}_{2}$ for polymer production, and the Bayer company expects its "dream products" to

9 become a commercial success. In the coming years, one may expect that new process

10 technologies, significantly enabled by catalyst research, will foster the use of $\mathrm{CO}_{2}$ in a

11 combination of higher energy efficiency, so that competitiveness need not be hampered

12 againts conventional fossil resources.

13 The coming years will reveal also to which extent a competition will develop between gas-

14 based power suppliers and chemical industry about the access to renewable SNG. The

15 multiple use of methane, including also the potentially large market for transport fuels, may

16 be an advantage for those who provide SNG based on renewable sources. The users, however,

17 may be interested to secure their supply by means of long-term contracts (as piloted by Audi).

18 On the long run, developing C-REC systems could make countries like Germany more

19 independent from external supply for energy and carbon carriers, in particular gas imports

20 from Russia.

19 for 2009, in: DESTATIS (2011): Umweltnutzung und Wirtschaft. Bericht zu den Umweltökonomischen GesaMMtrechnungen. Wiesbaden

20 IEA extended energy tables, data for 2007 
1 When considering the outlined possible C-REC routes, the realization will certainly start from

2 status quo, that means existing facilities and the given spatial distribution. In industrial

3 countries where chemical industry is interested to put their energy and material supply on a

4 renewable basis, and waste management needs to reduce their costs, the organization of

5 industrial symbiosis (Chertow and Ehrenfeld 2012) may be considered. Advancing the

6 knowledge base and the promotion of innovations towards this end (Lombardi et al. 2012),

7 may start from constellations such as:

- A fossil fired power supply company is located close to a chemical industry plant producing polymers; this situation is given where the RWE power company captures $\mathrm{CO}_{2}$ which is further used in the Bayer company for polyurethane production (see above).

- Similarly, a chemical industry plant may use its own power station for $\mathrm{CO}_{2}$ capture, pipeline it on short distance and methanize it with hydrogen produced in particular with power during periods when renewable energy input to the grid exceeds public demand. The chemical company may also use the $\mathrm{CO}_{2}$ directly in various syntheses. It may, however, also produce methane, and either use it for its own purposes, or feed the renewable SNG into the national pipeline system. Chemical industry could thus become a renewable power and energy supplier.

- A (thermal) waste treatment facility considers carbon capture, it has access to renewable power, in particular wind power and its peak load not used elsewhere, and it is connected or not to far from the natural gas pipeline net; it could then install the carbon capture, electrolysis and methanation on the spot and produce renewable methane. Supply contracts with chemical industry or transport organizations could provide a sustainable basis for commercial solutions. 
1 In countries like Germany where waste-to-energy is state-of-the-art, waste has become a

2 resource, waste management has grown a big business, and waste management facilities are

3 competing to get enough waste to fill their capacities. In other regions and countries like the

4 USA, where still most of the municipal waste is deposited in landfills, there seems to be less

5 competition between different users of the waste. This could enhance the chances to develop

6 C-REC routes when cities plan to establish more modern ways of waste management, trying

7 to minimize landfill space, and check options to minimize costs. If new facilities for solid

8 waste management are planned, one may consider the establishment of thermo-chemical

9 recycling of the carbon content. In particular in cities with chemical industries this could be

10 an option, and the recycling of organic waste into base chemicals can provide a more

11 favourable GHG balance (Nuss et al. 2012).

12 When considering the various options, also prices will certainly play a role, as well as long-

13 term factors influencing them. The recent price level of petroleum and natural gas as base

14 materials for chemical synthesis is still rather low. If SNG is to substitute natural gas or

15 petroleum for this purposes, the C-REC routes may become commercial with increasing

16 prices of $\mathrm{CO}_{2}$ emissions, and with technological development making processes more

17 efficient, which might also need further research and development.

18 Also the development of the future demand for carbon based products might play an

19 important role when considering investments into C-REC technologies. Currently, only a

20 rather minor portion of durable products is made of synthetics. This may not stay at this low

21 level. For instance, in car industry, the long-run development may turn to polymer-based car

22 bodies, as Formula 1 cars already show, and BMW is going to put a first electric car with a

23 carbon fibre body on the market. The car body of the future will most probably consist of a 
1 polymer matrix, most likely based on carbon compounds. It is interesting to see that the

2 development towards higher energy efficiency and the proceeding shift towards renewable energies promote also innovations of material use. Polymers are leightweight compared to traditional products of heavy industries. In the building sector, higher standards for energy efficiency also lead to an increased use of polymers, such as for insulation, and modern facades and roofs are increasingly made of polycarbonates. On the long run, carbon fibres and carbon-based fibres may even substitute for concrete, timber, and steel constructions to a significant extent.

9 With the further development of C-REC routes through technical recycling the design 10 strategies for plastics may also evolve further. The property of biodegradability which is 11 desirable to reduce the consequences of littering, in particular from packagings, might not be required at least for durable products collected for waste incineration with carbon recycling. Waste incinerators have also the advantage that - if properly conducted - they may act as sinks

14 for pollutants by destroying synthetic carbon molecule structures which may poise a hazard 15 for health and environment (van Caneghem et al. 2010). The C-REC option outline provides the chance to combine detoxification of the socio-industrial metabolism with the long-term recycling of a carrier material flow such as carbon.

While it is still wide-spread thinking that biomass based products might provide the long-term solution to sustainable materials and energy supply, this does not consider the growing conflicts between different types of land use and the limited capacities for sustainable food 21 and non-food biomass production. Only if functioning C-REC systems are established, the 22 rising pressure of the demand of biogenic carbon compounds on the natural eco-systems will 23 be effectively relieved. Then self-carrying recycling systems may be established which will 
1 be more and more driven by solar and wind energy. This will be the rerequisite for the

2 anthroposphere to develop towards a photoautotrophic system.

3

4 When investing into the further development of C-REC technologies it seems advisable to learn from piggy-back approaches but pass them rather quickly and focus on the establishment of self-carrying carbon cycles within the production and consumption system.

7 In the course of the German energy system change ("Energiewende") the supply of renewable energy, in particular from wind converters in the North will significantly increase, and so will the requirements to transport and store that energy. One key option will be the transformation into SNG as methane. Methane can play a key role for both energy and material supply, and

11 may be used as a main carrier of carbon and chemically bound energy. Of particular interest will be to study the potential synergy and competition between the technologies and

13 institutions enhancing the use of renewable energy versus renewable material supply and the 14 factors driving the transition.

15 The development of C-REC can be further explored from at least two starting points or 16 potential nuclei of future clusters: from waste management where carbon could be captured 17 and sold as raw material, and from chemical industry which could shift to recycled carbon sources and contribute even to public renewable energy supply. The challenge for research and development is to help further explore the different paths, and simulate the further possible development with a long-term time horizon and with a systems

21 perspective which covers the total socio-industrial metabolism and its resource use. 


\section{Acknowledgements}

2 The author would like to thank Dovile Staniatyte and Jelena Jovancevic for helpful

3 discussions and hints, and Marianne Schmid and Janina Ubachs for technical assistance.

\section{References}

5 ACRR - Association of Cities and Regions for Recycling 2004. Good practises guide on

6 waste plastics recycling. A guide by and for local and regional authorities. Brussels.

$7 \quad$ www.pvc.org/upload/documents/ACRRReport.pdf

8 Avérous, L. and E. Pollet. 2012. Biodegradable Polymers. In Environmental Silicate Nano-

9 Biocomposites; Green Energy and Technology edited by Avérous and Pollet, 13-39.

10 BDEW Bundesverband der Energie- und Wasserwirtschaft (Hrsg.). 2012. Energiemarkt

11 Deutschland: Zahlen und Fakten zur Gas-, Strom- und Fernwärmeversorgung. Frankfurt, 12 http://docs.dpaq.de/2436-energie-markt_2012d_web.pdf. Accessed 27 April 2013.

13 Bilitewski, B. 2006: Ökologische Effekte der Müllverbrennung durch Energienutzung.

14 Präsentation TU Dresden, 6.11.2006,

15 http://www.umweltbundesamt.de/abfallwirtschaft/nachhaltigkeit/dokumente/energie-aus16 abfall-verbrennung.pdf. Accessed 12 Feb 2013.

17 Bringezu, S. 2009: Visions of a sustainable resource use. In Sustainable resource 18 management : global trends, visions and policies edited by S. Bringezu and R. Bleischwitz, $19155-215$. 
1 Bringezu, S., M. O’Brien and H. Schütz. 2012: Beyond Biofuels: Assessing global land use

2 for domestic consumption of biomass. A conceptual and empirical contribution to sustainable

3 management of global resources. Land Use Policy, 29, 24-232.

4 Bringezu, S. 2013: Targets for global resource consumption. In Factor X. Policy, Strategies

5 20Verwertung\%20von\%20Kunststoffen\%20in\%20Deutschland. Accessed 28 May 2013. Dahmen, N. 2012: State of the Art of the Bioliq ${ }^{\circledR}$ Process for Synthetic Biofuels Production. In ENVIRONMENTAL PROGRESS \& SUSTAINABLE ENERGY 31: 176-181. Dena (Deutsche Energie-Agentur GmbH). 2011: Erdgas und Biomethan im künftigen Kraftstoffmix. Handlungsbedarf und Lösungen für eine beschleunigte Etablierung im

17 Verkehr, http://www.dena.de/fileadmin/user_upload/Presse/studien_umfragen/Erdgas_als_Kraftstoff/E 19 rdgas_und_Biomethan_im_kuenftigen_Kraftstoffmix.pdf. Accessed 28 April 2013. 
1 DESTATIS. 2013: Umwelt. Abfallentsorgung.Vorläufiger Ergebnisbericht für ausgewählte

2 Entsorgungsanlagen. Wiesbaden.

3 Graedel, T.E. and B.R. Allenby. 1995: Industrial Ecology. Upper Saddle River, NJ; Prentice 4 Hall.

5 Gurgel Adeodato Vieira, M., Altenhofen da Silva, M., Oliviera dos Santos, L. and M.M.

6 Beppu. 2011: Natural-based plasticizers and biopolymer films: A review. European Polymer

7 Journal 47, 254-263.

8 Hayes, D. J. 2009. An examination of biorefining processes, catalysts and challenges.

9 Catalysis Today, 145(1-2), 138-151.

$10 \mathrm{Hu}$, B., Guild, C. and S.L. Stuib. 2013: Thermal, electrochemical, and photochemical

11 conversion of $\mathrm{CO}_{2}$ to fuels and value-added products. J. $\mathrm{CO}_{2}$ Util., in press,

12 http://dx.doi.org/10.1016/j.jcou.2013.03.004.

13 IPCC. 2005: IPCC Special Report on Carbon Dioxide Capture and Storage. Prepared by

14 Working Group III of the Intergovernmental Panel on Climate Change. Cambridge University 15 Press, Cambridge, United Kingdom and New York, USA.

16 Kheshgi, H., de Coninck, H. and J. Kessels. 2012: Carbon dioxide capture and storage: Seven 17 years after the IPCC special report. Mitig Adapt Strateg Glob Change 17, 563-567. 
1 Lackner, K.S. 2009: Capture of carbon dioxide from ambient air. Eur. Phys. J. Special Topics $2176,93-106$.

3 Lackner, K. S. 2010: Washing carbon out of the air. Scientific American June 2010, 66-71.

4 Lombardi, R. D., Lyons, D., Shi, H., Agarwal, A. 2012: Industrial sybiosis. Testing the

5 boundaries and advancing the knowledge. Journal of Industrial Ecology 16, 2-7

6 Müller-Syring, G. 2011: Power to Gas: Untersuchungen im Rahmen der DVGW-

7 Innovationsoffensive zur Energiespeicherung. DVGW energie | wasser-praxis 4/2011, 72-77.

8 Odum, E. P. 1959: Fundamentals of Ecology. Philadelphia, Saunders.

9 Olah, G.A., Goeppert, A. and G.K. Surya Prakash. 2009: Beyond Oil and Gas: The Methanol

10 Economy. Second edition. Wiley-VCH Verlag, Weinheim.

11 Paulick, S. et al. 2013: Steel all over the world: Estimating in-use stocks of iron for 200

12 countries. Resources, Conservation and Recycling 71, 22-30.

PMRG - Plastics Europe Market Research Group 2012: Plastics - the Facts 2012. Brussels, Belgium. www.plasticseurope.co.uk/Document/plastics-the-facts-2012.aspx?Page=DOCUMENT\&FolID=2 
1 Rayner, C.M. 2007: The Potential of Carbon Dioxide in Synthetic Organic Chemistry. Org.

2 Process Res. Dev. 11: 121-132. DOI: 10.1021/op060165d.

3 Ritter, S.K. 2007: What can we do with $\mathrm{CO}_{2}$ ? Chemical \& Engineering News 85: 11-17.

4 PB (Parsons Brinkerhoff) and GCCSI (Global CCS Institute). 2011: Accelerating the uptake 5 of CCS. Industrial use of captured carbon dioxide.

6 http://www.globalccsinstitute.com/publications/accelerating-uptake-ccs-industrial-use-

7 captured-carbon-dioxide. Accessed 5 May 2013.

8 Ravve, A. 2012: Principles of Polymer Chemistry. 3rd edition, Springer; New York,

9 Heidelberg, Dordrecht, London.

10 Ren, T., Patel, M.K. and K. Blok. 2008: Steam cracking and methane to olefins: energy use,

$11 \mathrm{CO}$ emissions and production costs. Energy 33/5, 817-833.

12 Soorholtz, M., White, R.J., Zimmermann, T., Titirici, M.-M., Antonietti, M., Palkovits, R. and

13 F. Schütz. 2013: Direct methane oxidation over Pt-modified nitrogen-doped carbons. Chem.

14 Commun. 49, 240-242.

15 Siracusa, V., Rocculi, P., Romani, S. and M. Dalla Rosa. 2008: Biodegradable polymers for 16 food packaging: a review. Trends in Food Science \& Technology 19, 634-643. 
1 Sterner, M., Jentsch, M. and U. Holzhammer. 2011: Energiewirtschaftliche und ökologische

2 Bewertung eines Windgas-Angebotes. Gutachten Fraunhofer Institut für Windenergie und

3 Energiesystemtechnik (IWES), Kassel, Germany.

4 Stünkel, S., Trivedi, H., Godini, H.-R., Jaso, S., Holst, N., Arndt, S., Steinbach, J. and R.

5 Schomäcker. 2012: Oxidative Coupling of Methane: Process Design, Development and

6 Operation in a Mini-Plant Scale. Chemie Ingenieur Technik 84, 1989-1996.

7 Styring, P., Jansen, D., de Coninck, H., Reith, H. and K. Armstrong. 2011: Carbon capture

8 and utilisation in the green economy. Using $\mathrm{CO}_{2}$ to manufacture fuel, chemicals and

9 materials. Report No. 501. The Centre for Low Carbon Futures. Birmingham

10 Sumio, Y., Shimizu, M. and M. Fumihiro. 2004: Thermoselect Waste Gasification and

11 Reforming Process. JFE Technical Report No. 3, http://www.thermoselect.com/news/2004-

12 07\%20JFE\%20Technical\%20Report\%20Thermoselect\%20Process.pdf.

13 Themelis, N. J. 2007: Thermal treatment review: Global growth of traditional and novel

14 treatment technologies. In Waste Management World, July - August 2007: 37-45, available at:

15 http://www.cleanenergycouncil.org/files/Themelis_WMW_2007.pdf.

16 Umweltbundesamt (Hrsg.). 2013: Nachwachsende Rohstoffe, http://www.umweltbundesamt-

17 daten-zur-umwelt.de/umweltdaten/public/theme.do?nodeIdent=2281. Accessed 3 May 2013. 
1 Van Caneghem, J., Block, C., Van Brecht, A., Wauters, G. and C. Vandecasteele. 2010:

2 Mass balance for POPs in hazardous and municipal solid waste incinerators. Chemosphere $3 \quad 78: 701-708$.

4 VDP - Verband deutscher Papierfabriken. 2013: Papier Kompass 2013, http://www.vdp-

5 online.de/de/papierindustrie/statistik.html. Accessed 27 May 2013.

6 VCI and DECHEMA. 2009: Utilization and Storage of CO. Positioning paper of the German

7 Association of the Chemical Industry and the Society for Chemical Engineering and

8 Biotechnology,

9 http://www.dechema.de/dechema_media/Downloads/Positionspapiere/Positionspapier_co2_e

10 nglisch.pdf. Accessed 27 May 2012.

11 Volkswagen AG. 2012: Audi e-gas project is milestone for sustainable mobility, press release

1213 Dec 2012,

13 http://www.volkswagenag.com/content/vwcorp/info_center/en/themes/2012/12/audi_e_gas_p

14 lant.html. Accessed 27 April 2013.

15 Weiss, M., Haufe, J., Carus, M., Brandao, M., Bringezu, S., Hermann, B. and M. K. Patel. 16 2012: A Review of the Environmental Impacts of Biobased Materials. Journal of Industrial 17 Ecology 16, 169-181. 
1 Wilson, E.J., Friedmann, S.J. and M.F. Pollak. 2007: Research for deployment: incorporating

2 risk, regulation, and liability for carbon capture and sequestration. Environ. Sci. Technol. 41, $3 \quad 5945-5952$.

4 Zah, R., Binder, C., Bringezu, S., Reinhard, J., Schmid, A. and H. Schütz. 2010: Future

5 perspectives of 2 nd generation biofuels. Centre for Technology Assessment, TA-SWISS

6 55/2010. Vdf Hochschulverlag AG an der ETH, Zürich.

7 Zero Emission Platform (European Technology Platform for Zero Emission Fossil Fuel

8 Power Plants). 2011: The Costs of $\mathrm{CO}_{2}$ Capture: Post-demonstration CCS in the EU,

9 http://www.zeroemissionsplatform.eu/library/publication/166-zep-cost-report-capture.html.

\section{About the author}

12

13 Stefan Bringezu is director at the Wuppertal Institute where he heads the research group on

14 Material Flows and Resource Management, and professor for sustainable resource

15 management at the Centre for Environmental Systems Research (CESR) at Kassel University,

16 Germany, where he co-chairs the group on Sustainable Resource Futures (SURF).

17 Corresponding author's contact: bringezu@cesr.de

18 Mailing address: Wuppertal Institute, P.B. 100480, 42004 Wuppertal, Germany 